\title{
Research on Problems of Tourist Traffic Management in the North Scenic Area of Changbai Mountain*
}

\author{
Mingju Liu \\ Yatai School of Business \\ Jilin University of Finance and Economics \\ Changchun, China 130117
}

\author{
Liguang Zhao \\ School of Taxation \\ Jilin University of Finance and Economics \\ Changchun, Jilin, China 130117
}

\author{
Wen Ouyang \\ Yatai School of Business \\ Jilin University of Finance and Economics \\ Changchun, China 130117
}

\begin{abstract}
As the first batch of national 5A level scenic area, the north scenic area of Changbai Mountain has attracted large amounts of tourists at home and abroad with picturesque and marvelous natural scenery and rich and long cultural deposits and has become the tourist attraction renowned in the world. With rapid development of national economy and continuous improvement of living standard of people, the number of tourists received by scenic spots in different places of our country yearly including the North scenic area of Changbai Mountain is increasing significantly, accompanying with problems such as traffic jam in it. This paper introduces current situation of tourist traffic in the North scenic area of Changbai Mountain and analyzes management of traffic inside the scenic area and proposes reasonable suggestions to improve the management of tourist traffic inside the North scenic area of Changbai Mountain.
\end{abstract}

Keywords-the north scenic area of Changbai Mountain; tourist traffic; traffic management

\section{INTRODUCTION}

Located in southeast Jilin province, Changbai Mountain is the highest mountain in the east of Eurasia as well as the boundary of China and North Korea. Changbai Mountain is the cradle of people of all ethnic groups in northeast China, the birthplace of Ruzhen, the forefather of Manchu and the ecological shelter zone of three provinces in the northeast of China. It has been regarded as "Sacred Mountain" since ancient times. Changbai Mountain is the gathering place of Korean people. Full-bodied folk customs of the Korean nationality combines with the long historic culture, forming the unique charm of Changbai Mountain.

The north scenic area of Changbai Mountain is located in the North Slope of Changbai Mountain, about 34 kilometers away from Changbai Mountain and the southeast of it is adjacent to North Korea. As the first batch of national 5A scenic area, the north scenic area of Changbai Mountain has

Fund project: National Natural Science Foundation of China (project number: 41401146); Science and Technology Development Project in Jilin Province (201502040NY). attracted large quantities of domestic and foreign tourists with distinctive characteristics such as "crater lake, snow mountain, Tracks in the Snow Forest, hot spring, cirque and rime" and becomes world-famous resort. At present, the main scenic spots in the north scenic area of Changbai Mountain include the Changbaishan Tianchi, Changbai Waterfall, Underground Forest and Hot Springs Group. Changbai Mountain is also famous for its mysterious and grand volcanic landform and typical and complete forest ecosystem. Influenced by geographical location, the winter of Changbai Mountain is long and cold. The number of tourists is smaller than that in summer. It has strong tourism seasonality. The best time for tourist to tour the north scenic area of Changbai Mountain is during July and September in every year. The number of tourists and tourist income during this time occupy about $70 \%$ of the whole year. Moreover, the Erdaobaihe Town located at the foot of Changbai Mountain is only 35 kilometers away from Changbai Mountain. It is the gateway of Changbai Mountain, reputed as "the First Town of Changbai Mountain".

Changbai Mountain is world-famous tourist destination because tourist can "walk in the snow and enjoy beautiful flowers in spring, avoid summer heat and take a holiday in summer, see serried woods deep-dyed in autumn and tour kingdom of snow in winter". According to data report of government affairs network of Changbai Mountain, during the "12th Five-Year Plan" (from 2011 to 2015), the number of tourists and tourist income of Changbai Mountain realizes new growth. On one hand, the number of tourists received breaks through 10 million and reaches up to 12.304 million. In the single year of 2015 , the number of tourists received is 3.13 million, two times of the number in 2010, with average annual growth rate of $15.2 \%$. On the other hand, the tourist income breaks through ten billion and reaches up to 11.036 billion yuan. In the single year of 2015, the tourist income reaches 2.976 billion yuan, 2.6 times of the number in 2010, with average annual growth rate of $21.2 \%$.

There are a wide range of animals and plants in Changbai Mountain. It is the most representative typical natural complex 
in the north of Eurasia and the rare "species gene bank" and "natural museum" in world range. To protect forest ecosystem in temperate zone, natural historic relics and rare animals and plants, as early as in 1960, Changbai Mountain had established natural conservation area and became national nature reserve in 1986. The UNESCO listed it in international biosphere reserve network in 1980, as one of the world's nature reserves. In August 1992, the nature reserve of Changbai Mountain was ranked as level A nature reserve with international significance by the World Conservation Union. In January 2006, the Management Committee of Changbai Mountain Protection Zone was established formally, belonging to department level, equal to the position of prefecture-level city. Three economic management areas, Chixi, Chibei and Chinan and five administrative villages are under its administration. It takes charge of the scope of more than 6,000 square meters in and around Changbai Mountain.

\section{CURRENT Situation OF TOURIST TrafFic IN NORTH SCENIC AREA OF CHANGBAI MOUNTAIN}

\section{A. External Traffic}

In air traffic, Changbai Mountain has the first forest tourism airport in our country, Changbaishan Airport, which is located in Chixi District, about 120 kilometers away from the north scenic area of Changbai Mountain. At present, it has opened the flights to Changchun, Beijing, Shenyang, Shanghai and Yanji. Airports also exist in Changchun and Yanji. Chaoyangchuan International Airport in Yanji is nearest to Changbai Mountain, with only three to four hours of range of driving. Chaoyangchuan International Airport also opens flights to Beijing and Shanghai and non-stop flight to South Korea.

In railway traffic, Baihe Station is located in Erdaobaihe Town of Antu County, only 35 kilometers away from the north scenic area of Changbai Mountain, the nearest railway station to the north scenic area of Changbai Mountain. At present, nonstop special railway lines in Shenyang, Changchun and Beijing have opened to Baihe Station. Besides, tourists can choose Antu Station and Dunhua Station near to Baihe Town and then drive to Baihe Town or by bus. It deserves to be mentioned that the Jilin-Tumen-Huichun High Speed Rail had opened and operated on September 20, 2015. It is renowned as "the Most Beautiful High Speed Rail in the Northeast China", connecting many scenic spots such as Songhua Lake, LAFA Mountain National Forest Park, Hongye Valley in Jiaohe city, Jingpo Lake and Liuding Mountain in Dunhua city and Changbai Mountain. It is of great significance to drive the tourist development of Changbai Mountain and Tumen River area and strengthen exchange and cooperation of Northeast Asian region.

In road traffic, now national highway 201, national highway 202 and secondary road 302 line pass through Baihe Town. There are also national highways or provincial roads connecting Dunhua city, Yanji city, Tonghua City with Baihe Town. The north scenic area of Changbai Mountain has opened travel express minibus, the price of which ranges from 8.5 yuan to 23 yuan. It can transport tourists directly from
Baihe Town to the gate of north scenic area of Changbai Mountain, cheap and convenient for most tourists.

\section{B. Internal Traffic}

The main scenic spots in the North Slope of Changbai Mountain are in linear distribution from the entrance door to Tianchi, including Underground Forest, Luyuantan Pool, Small Tianchi, Hot Springs Group, Changbai Waterfall and Tianchi in Changbai Mountain. A comprehensive transfer center exists between Underground Forest and Luyuantan Pool in the scenic spot; Luyuantan Pool has Lanjing restaurant with big scale for tourists to have a rest; Hot Spring Group has parking lot with big area for vehicles to transfer; they ensure each scenic spot has parking spot for tourists; the chief dispatcher responsible for vehicle dispatch commands at the ticket office every day. Each scenic spot has one vehicle dispatcher to dispatch vehicles. In busy season, traffic assistants are sent to help the vehicle dispatchers according to specific situation. Dispatchers use wireless transceiver to communicate.

Because the mountain is steep and the surrounding terrain is strategically located and difficult of access, to ensure safety and environmental protection, at present, the north scenic spot of Changbai Mountain has implemented closed-off management and strictly forbidden private cars to enter. Environment-friendly big buses with air conditioners, low emissions and low energy consumption that use clean energy are used in the scenic area. When buying the tickets, tourists must by tickets of the big bus. Tourists use the ticket bus ticket to tour all scenic spots except for Tianchi and transfer in different scenic spots. Because Tianchi is located in the main peak of Changbai Mountain, with high altitude and steep and winding road, tourists need to go to Tianchi by special "transfer bus" in the transfer center. The transfer bus ticket is sold at the transfer center with the price of 80 yuan per person. It depends on the tourists whether to visit Tianchi or buy transfer bus ticket. It needs about 30 minutes to drive from the transfer center to Tianchi.

Besides, plank roads are paved between Changbai Waterfall, Hot Springs Group and Small Tianchi, between Small Tianchi and Luyuantan Pool. In busy season, the scenic spots often decide whether need to open the plank road to the tourists according to passenger flow volume and the weather conditions. Tourists can choose to walk on the plank road to the next scenic spot. It helps them to place themselves in the beautiful scenery of the nature and enjoy the charm of Changbai Mountain, but tourists need to have corresponding physical power and patience; tourists can also choose to queue up at the parking spot to wait for the big bus and go to the next scenic spot. It can save physical power, but the time is uncertain, tourists may waste a lot of time and delay the travel. Because the highway in the scenic spot is full of twists and turns and landslide may exist, to ensure safety, the scenic spots forbid tourists to walk on the highway arbitrarily and step into the dangerous zone by stepping over the plank road, except for relying on the big bus and plank road to transfer between scenic spots. 


\section{PROBLEMS EXISTING IN INTERNAL TOURIST TRAFFIC MANAGEMENT IN THE NORTH SCENIC AREA OF CHANGBAI MOUNTAIN}

\section{A. The Existing Environment-friendly Big Bus Is Difficult to Meet the Demands of Tourists}

Under normal conditions, the tour route popular among most tourists is: take environment-friendly big bus at the entrance of the scenic spot to reach the transfer center. If tourists need to visit Tianchi, they get off at the transfer center and buy transfer bus ticket to go to Tianchi; after visiting Tianchi, they return to the transfer center and transfer to environment-friendly big bus to visit Changbai Waterfall, Hot Springs Group, Small Tianchi and Luyuantan Pool and Underground Forest successively. If tourists do not need to visit Tianchi, they directly transfer to the environment-friendly big bus to go to the Changbai Waterfall and other scenic spots successively. Finally, they return to the entrance of the scenic spot and end this tour. Even though the tourists do not visit Tianchi, they must get off when reaching the transfer center, because the environment-friendly big bus needs to transport passengers at the entrance. Tourists need to queue up to wait for the big bus that goes to Changbai Waterfall. That is to say, the environment-friendly big buses include the big buses responsible for the section of highway between the entrance and the transfer center and big buses responsible for the section of highway between the transfer center and the Changbai Waterfall. At the meantime, the scenic area stipulates that the big bus must keep going in each direction, namely, the big bust will not stop when leaving from the entrance to the transfer center and from the transfer center to the Changbai Waterfall.

Although most tourists will choose the above tour route, in reality, not all the tourists have the same choice. Some tourists get off at the Small Tianchi, some at the Underground Forest and some at the Luyuantan Pool. However, the scenic area forbids environment-friendly big bus to stop in travel. Sometimes the tourists may be in the dilemma that they cannot get on the big bus. In this way, contradictions form between the tour route that meets demands of most tourists and the tour route that meets demands of a small part of tourists.

Because the number of tourists is huge, especially in busy season, if the scenic spots meet the requirements of each or each batch of tourists to allow the big bus to stop at scenic spot required by the tourists, it will inevitably disrupt the order of tourist traffic in the scenic spot and reduce the operating efficiency of environment-friendly big bus. Above all, it is the most appropriate and scientific way for environment-friendly big bus to send tourists to Changbai Waterfall and then the tourists visit Hot Springs Group, Small Tianchi, Luyuantan Pool and Underground Forest successively. It is also the tour route that exerts the minimum pressure on tourist traffic in the scenic spot. Therefore, the existing traffic rules for environment-friendly big bus in the scenic area are practical and reasonable.

Tourists of course have the rights to visit scenic spots not taking the ordinary tour route but using the tour route of their own to get off in each scenic spot. Under normal circumstances, environment-friendly big bus will cooperate when tourists require. However, when tourists want to leave for other scenic spots after visiting this scenic spot, they will get on the big bus smoothly if they want to go down the mountain to visit; but it is difficult for them to get on the bus if they want to go up the mountain to visit. In this case, tourists can choose to take the descending environment-friendly big bus to the transfer center and then take the ascending bus to visit other scenic spots, but it will greatly shorten the visiting time and lower the quality of sightseeing.

\section{B. The Infrastructure of Tourist Traffic in the Scenic Spot Is Not Perfect}

In busy season of every year, tourists from all over the world come to visit the north scenic area of Changbai Mountain. The sharp increase of tourist number brings great challenge for the tourist traffic of the scenic area. Large quantities of tourists queue up to wait for the bus or have a rest at the ticket examiner, temporary parking spots and Lanjing Restaurant. Tourists are easy to gather at the Changbai Waterfall and Hot Springs Group, because they are close to each other and share the same parking lot in the Hot Springs Group. After visiting Changbai Waterfall and Hot Springs Group, the number of tourists queuing up at the parking lot to wait for the bus will increase sharply within a short period of time, and then the place is packed. To cope with the operating pressure of environment-friendly big bus, calm down the anxious tourists and ensure their safety, the scenic spot will open the plank road (1,500 meters) between Hot Springs Group and the Small Tianchi if the weather is fine to divide the tourists and relieve the tourist traffic pressure. It depends on the tourists to continue to queue up and go to the next scenic spot or walk to the next scenic spot on the plank road.

Although when the parking lot is overcrowded, the scenic spot will not open the plank road to tourists easily. They must consider the weather conditions comprehensively at that time. If the weather is fine, they will decide to open the plank road to tourists and notify staff at scenic spots to make corresponding preparations. However, the weather on Changbai Mountain is constantly changing. It may change for many times in a day even one hour. Sometimes the sun is shining fiercely, but cloud and mist hang over and rain falls in torrents all at once; sometimes the raindrops are continuous, but suddenly the sun is shining brightly. The scenic spot decides to open the plank road to tourists when the weather conditions permit. Staffs at the Hot Spring Group tell tourists they can walk to the Small Tianchi through the plank road. In order to save time wasted in waiting for the bus, some tourists will walk on the plank road. The plank roads in the north scenic area of Changbai Mountain are built near the mountain or pass through the forest. Sometimes when tourists are walking on it, it rains cats and dogs or a heavy gale is blowing. Besides, there are no places for tourists to take shelter from rain or the gale on the way. Most tourists often have no countermeasures and they are in difficult position after reaching the Small Tianchi. At this time, most tourists complain, even are angry about working staff at the Small Tianchi and call their names. It not only greatly breaks the 
normal order in the scenic spot but also seriously damage the overall image of Changbai Mountain.

\section{Working Staff at Different Scenic Spots Cannot Coordinate with Each Other Very Well}

Meanwhile, when notifying tourists who can walk to the next scenic spot through the plank road, working staffs at the Hot Springs Group often unconsciously "exaggerate" or "slight over" because they are busy in dividing tourists or finishing their work as soon as possible. They often say, "it will be easy to wait for the bus after walking to the next scenic", "it is better to walk through the plank road than wait here. You will finish the journey on the plank road within half an hour". These words with thick subjective color lead to the result that after most tourists reach the Small Tianchi, even though the weather does not change, they will complain to or scoff the working staff at Small Tianchi.

The first reason is that the plank road between Hot Springs Group and Small Tianchi is 1,500 meters long, full of twists and turns and the gradient of stairs is large. Tourists cannot "finish the journey on the plank road within half an hour" as the working staff say. Although some tourists feast their eyes on scenery in Changbai Mountain and find pleasure in it when walking through the plank road, in reality, most tourists feel they are "deceived" and think they waste a lot of time and physical energy on the plain plank road and then the journey is delayed.

The second reason is that there is only one temporary parking spot in Small Tianchi. Not every environment-friendly big bus will spot when passing Small Tianchi. The big bus often depart when there is no vacancy from the Hot Springs Group and stop at the Small Tianchi only when tourists require to visit Small Tianchi, so the tourists are restricted after they reach Small Tianchi from Hot Springs Group and hope to take the big bus. When tourists get off at Small Tianchi, working staff will also broadcast or orally inform tourists at the entrance to directly walk on the plank road of 650 meters long after they visit Small Tianchi and reach Luyuantan Pool and do not suggest tourists to return to the entrance. Once tourist groups with large number of people reach Small Tianchi from Hot Springs Group and the big bus does not stop or even though it stops but there are few tourists get off, there will be large number of tourists delay at Small Tianchi. The difficulty in taking bus only "transfer" from Hot Springs Group to Small Tianchi. The problem is not solved thoroughly.

\section{MEASURES TO IMPROVE INTERNAL TOURIST TRAFFIC MANAGEMENT IN NORTH SCENIC AREA OF CHANGBAI MOUNTAIN}

\section{A. Implement "Different Ticket Price" to Spare No Effort to Coordinate with Tourists Who Have Special Tour Routes}

At present, the rules on environment-friendly big bus in north scenic area of Changbai Mountain is most scientific and appropriate to impose the minimum pressure on tourist traffic in the scenic area. The number of tourists in north scenic area of Changbai Mountain is huge. In busy season of every year, the number of tourists every day reaches up to 10,000 easily. It is uncontroversial that the scenic area cannot meet demands of all tourists. But under the premise that keeps the current rules on environment-friendly big bus, the scenic spot can endeavor and try to coordinate with tourists who have special tour route. Firstly, the scenic spot can distribute small tourist manual and guide tourists with special tour route to take the tour route specified by the scenic area. Secondly, if tourists still insist on their own tour route, the scenic area can use "different ticket price" to divide these special tourists. That is to say, lower the ticket price for tourists with special tour route at Saturday, Sunday and Holidays and Festivals.

\section{B. Continue to Intensify the Construction of Tourist Traffic Facilities to Improve Satisfaction Degree of Tourists}

Because the weather is the most changeful on Changbai Mountain, the scenic area should build some pavilions and cabins along the plank road for tourists to have a rest. Moreover, to handle with the increasing number of tourists, the scenic area should consider enlarging the area of parking lots in corresponding scenic spots. For example, to avoid the disorder caused by stranded tourists, the Small Tianchi is in urgent need of a big parking spot.

\section{Strengthen Coordination, Communication and Cooperation between Working Staffs of Each Scenic Spot}

Working staffs in north scenic area of Changbai Mountain have worked here for many years. They are familiar with the situation here. However, the phenomenon mentioned above also happen. On one hand, working staffs of the last scenic spot work hard to divide the tourists and their behaviors without viciousness make working staffs of the next scenic spot ensure the precipitate scold from tourists, which break normal order of the scenic area and obstruct normal operation of traffic in the scenic area. For important tasks involving working condition of many scenic spots, working staffs should communicate and notify the dynamic changes in real time, so that it helps to improve the operational efficiency and quality of tourist traffic. The scenic area can provide a place at the entrance of each scenic spot to record the real-time passenger flow volume and then reasonably divide and control correspondingly.

\section{CONCLUSION}

The rapid development of tourist traffic in the North scenic area of Changbai Mountain improves operating efficiency of the scenic spot, at the same time improves the satisfaction degree of tourists, and then helps the virtuous cycle, faster and better development of the Changbai Mountain, to drive fast development of tourist industry of Jilin province and make positive contributions to economic development of Jilin province.

\section{REFERENCES}

[1] Du Youzhen, Pei Yuchang, Wu Hongliang. Introduction to Tourism [M], Chongqing: Southwest China Normal University Press, 2007

[2] Bao Jigang, Chu Yifang. Tourist Geography [M], Beijing: Higher Education Press, 1999 
[3] Wang Juan. Discussion on Application of Intelligent Transportation System in Jouzhaigou Valley Scenic Area Management and Operational Evaluation [D], Southwestern University of Finance and Economics, 2007

[4] Wang Yan. Detailed Plan of Dunhuang Yang Guan Scenic Area and Visualization Research on Its Important Nodes [D], Xi'an University of Science and Technology, 2012

[5] Zhang Yi. Research on Management and Planning of Traffic Demand in Tourist Attraction-Take Fenghuang Ancient City as an Example [J], Highways and Automotive Applications, 2014(2)

[6] Feng Peiyu, Li Wenquan. Analysis on Comprehensive Traffic Planning in Tourist Attraction -Take Changbai Mountain as an Example [N], Journal of Transportation Engineering and Information, 2014

[7] Zhao Xinggang, Gao Ang. Research on Tourist Traffic Planning Methods under the Background of Leisure Vacation Tour-Take Thousand-island Lake Scenic Area as an Example [J], Urban Age, 2013(3)

[8] Tian Qing. Thinking on "Characteristic" Transportation Planning and Design in Tourist Attraction [J], Environmental Art, 2014(5) 